\title{
Intercellular transfer of small RNAs from astrocytes to lung tumor cells induces resistance to chemotherapy
}

\author{
Assaf Menachem ${ }^{1}$, Victoria Makovski ${ }^{1}$, Or Bodner $^{1}$, Metsada Pasmanik-Chor ${ }^{2}$, Reuven \\ Stein ${ }^{1}$, Noam Shomron ${ }^{3}$, Yoel Kloog ${ }^{1}$ \\ ${ }^{1}$ Department of Neurobiology, Tel Aviv University, 69978 Tel Aviv, Israel \\ ${ }^{2}$ Bioinformatics Unit, The George S. Wise Faculty of Life Sciences, Tel Aviv University, 69978 Tel Aviv, Israel \\ ${ }^{3}$ Department of Cell and Developmental Biology, Sackler Faculty of Medicine, Tel Aviv University, 69978 Tel Aviv, Israel \\ Correspondence to: Assaf Menachem, e-mail: assafmena@gmail.com \\ Yoel Kloog, e-mail: kloog@post.tau.ac.il
}

Keywords: astrocytes, small RNA, lung tumor, intercellular transfer, chemotherapy

Received: October 04, 2015

Accepted: January 23, 2016

Published: February 09, 2016

\section{ABSTRACT}

Brain metastases are resistant to chemotherapy and carry a poor prognosis. Studies have shown that tumor cells are surrounded by activated astrocytes, whose cytoprotective properties they exploit for protection from chemotherapy-induced apoptosis. The mechanism of such astrocytic protection is poorly understood. A non-mutational mechanism of resistance to chemotherapy that is receiving increased attention is the regulation of gene translation mediated by small noncoding RNAs (sRNAs), and particularly microRNAs (miRNAs). With the aim of examining the role of astrocytic sRNAs in promoting resistance of human lung tumor PC14 cells to chemotherapy-induced apoptosis, here we used a miRNA microarray to compare sRNA profiles of human lung tumor cells cultured with and without astrocytes. We found that SRNAs are transferred from astrocytes to PC14 cells in a contact-dependent manner. Transfer was rapid, reaching a plateau after only 6 hours in culture. The sRNA transfer was inhibited by the broad-spectrum gap-junction antagonist carbenoxolone, indicating that transfer occurs via gap junctions. Among the transferred sRNAs were several that are implicated in survival pathways. Enforced expression of these sRNAs in PC14 cells increased their resistance to the chemotherapeutic agent paclitaxel. These novel findings might be of clinical relevance for the treatment of patients with brain metastases.

\section{INTRODUCTION}

According to the American Cancer Society, approximately 1.6 million new cases of cancer are reported each year in the United States, and up to $40 \%$ of those patients will develop brain metastases [1,2]. The incidence of brain metastases has been increasing due to improved imagine techniques, such as magnetic resonance imaging, enabling early detection in asymptomatic patients, and to effective systemic treatments that can prolong life, allowing the cancer to disseminate to the brain [3]. Brain metastases are becoming a major challenge in therapy and prevention. Current therapies for brain metastases include surgery, radiotherapy and in a limited manner, chemotherapy [3]. Over recent decades it has become clear that malignancy is controlled by interaction between tumor cells and the stromal cells, connective tissue cells that support and maintain the function of an organ's parenchymal cells [4]. In cancer, stromal cells modify the neoplastic properties of the tumor cells and contribute to their proliferation [5-7]. The brain cells that correspond to stromal cells are the astrocytes, which are the most abundant of all cell types in the human brain and perform a variety of functions in the central nervous system (CNS) [8]. The communication between tumor cells and the CNS cells is crucial for tumor cells thriving and survival, and can impact their sensitivity to chemotherapy [9-11].

Brain metastases are highly resistant to chemotherapy and carry a poor prognosis $[12,13]$. Until recently, the resistance of brain metastases to 
chemotherapeutic drugs was attributed to the presence of the blood-brain barrier (BBB) and efflux transporters such as p-glycoprotein $[13,14]$. Recent data have revealed, however, that around metastatic lesions the $\mathrm{BBB}$ is permeable, and clinical trials combining chemotherapeutic drugs with p-glycoprotein inhibitors have failed to reverse tumor-cell resistance $[13,15,16]$. Thus, other factors in the brain microenvironment, such as astrocytes, have been suggested to contribute to this resistance. In line with this idea it was shown that tumor cells are surrounded by activated astrocytes which, by means of several mechanisms [17-19], protect tumor cells from chemotherapy-induced apoptosis in a contact-dependent manner [17-19]. They achieve this, for example, by sequestering calcium from the tumor-cell cytoplasm, or by up-regulating genes such as BCL2L1, TWIST1 and GSTA5, which regulate cell survival [18, 19]. Alternatively, bidirectional signaling between astrocytes and cancer cells, mediated by the endothelin axis, upregulates survival genes in the tumor cells and protects them from chemotherapy [17].

Unfortunately, the clinical efficacy of chemotherapeutic drugs is limited because some tumors are resistant or develop resistance to the drugs. As a result, tumors often relapse aggressively and metastasize to distant organs, with devastating outcomes [20]. The causes of resistance to cancer drugs are thought to be linked to random genetic mutations, karyotypic changes and epigenetic changes causing alterations in gene function [21-24]. An important non-mutational mechanism of resistance to chemotherapy that has recently attracted much research attention is the regulation of gene translation mediated by small non-coding RNAs (sRNAs), in particular microRNAs (miRNAs). sRNAs are small non-coding RNA molecules that participate in gene regulation via base paring with complementary sequences within the messenger RNA, resulting in gene silencing $[25,26]$. There are several classes of sRNAs including miRNAs, siRNAs and Piwi-interacting RNAs (piRNAs) [27]. Over the last few years it has become increasingly clear that abnormal miRNA expression plays an important role in anti-cancer drug resistance [28-32]. Several studies have demonstrated abnormal expression of miRNAs in brain tumors. Some miRNAs were found to be upregulated and others were downregulated [33]. For example, miR17 is upregulated in glioma tissues and is associated with advanced pathological stage and with poor survival [34]. Another study has shown that reducing miR-17 increases cell viability and apoptotic activity [35].

It is well established by now that sRNAs act non-autonomously, with signals spreading from cell to cell [36]. They were shown, for example, to be spread by exosomes [37-39]. An additional mechanism, demonstrated for the first time by our group, is transfer mediated by cell-to-cell contact [40]. This study showed that both endogenously and virally encoded miRNAs are transferred from $\mathrm{B}$ to $\mathrm{T}$ cells [40]. The acquired miRNAs were functional, and acted by down-regulating the expression of their specific targets in the adopting $\mathrm{T}$ cells. Transfer of functional sRNAs between cells was also demonstrated in other cell systems, such as heart cells and human glioma cells [41, 42]. Sharing of miRNAs between cells was found to be important in interactions between cells in the tumor microenvironment and cancer cells. Thus, for example, miRNAs acquired by breast cancer cells from bone-marrow stromal cells can elicit cellcycle quiescence in the recipient cells through targeting of CXCL12 [43]. Several mechanisms have been proposed to mediate miRNA transfer. These include the exosomes, [44] and gap junctions [41-43]. In the brain, oncosomes, loaded with proteins, DNA and miRNAs, are transferred from one cell to other, and can affect the recipient cell's physiology, tumor proliferation, angiogenesis and invasion [33].

Our understanding of the interaction between tumor cells and the microenvironment has improved greatly over the last few years, but we still have only limited knowledge of how tumor cells and cells in their surrounding microenvironment affect each other by sRNA exchange or how such exchange contributes to malignancy. In the present study we focused on the potential transfer of sRNAs from astrocytes to metastatic lung tumor cells and its outcome for resistance of the tumor cells to chemotherapy. Our experimental system was based on the co-culturing of conditioned immortalized mouse astrocytes (H-2K b-tsA58 mice [45]; hereafter 'astrocytes') with the human lung adenocarcinoma PC14 cell line. Studies based on this cell system [17-19] have shown that co-culturing of astrocytes with PC14 cells provides contact-dependent protection of the tumor cells from toxicity of the chemotherapeutic drug paclitaxel (Taxol), rendering this system suitable for assessing the role of sRNA transfer in the astrocytic effect on tumor cells. It is possible that the co-cultured tumor cells might respond with less intensity to the astrocytes than the corresponding primary tumor cells. Our results showed that sRNAs are transferred from astrocytes to PC14 cells through gap junctions, and suggest that such transfer can protect tumor cells from chemotherapy. These novel findings are potentially of clinical relevance, and might lead to the development of new approaches for treating patients with brain metastases.

\section{RESULTS}

\section{Astrocytes protect PC14 tumor cells from toxicity of paclitaxel}

To examine the mechanism whereby astrocytes can promote protection of $\mathrm{PC} 14$ cells from apoptosis induced by the chemotherapeutic agent paclitaxel (Taxol), we incubated a co-culture of astrocytes and PC14 cells with $5 \mathrm{nM}$ Taxol for $48 \mathrm{~h}$ and then analyzed the cells. Apoptosis 
was assessed by staining with annexin-V and propidium iodide (PI), a well-known method for apoptosis detection. A representative dot plot of fluorescence-activated cell-sorting (FACS) analysis of the treated cells by annexin-V-FITS and PI staining is shown in Figure 1A. PC14 cells (CD340 positive) that were cultured with astrocytes contained a significantly higher percentage of live cells than PC14 cells cultured in the absence of astrocytes or when the two cell populations were separated using a transwell (Figure 1B; mean \pm SEM, $69 \pm 0.8 \%$, $52 \pm 2.6 \%$, and $36.8 \pm 3.7 \%$ respectively). In addition, PC14 cells co-cultured with astrocytes demonstrated a significant decrease in the percentage of apoptotic cells (Figure 1C; mean \pm SEM, $13.2 \pm 0.8 \%, 24.4 \pm 2.6 \%$, and $36.8 \pm 3.7 \%$ respectively). Taken together, these results show that astrocytes protect PC14 cells from Taxol-induced apoptosis, and that direct contact is required for this effect.

\section{Transfer of synthetic sRNA from astrocytes to PC14 cells}

To examine whether sRNAs can be transferred from astrocytes to $\mathrm{PC} 14$ cells, we co-cultured astrocytes-22bpCy3 (astrocytes transfected with synthetic sRNA analogous to mature sRNA conjugated with Cy3 fluorophore) with PC14 cells. After 1.5 h, 6 $\mathrm{h}$, or $24 \mathrm{~h}, 22 \mathrm{bpCy} 3$-containing PC14 cells (CD340 positive) were identified by FACS analysis. As shown in Figure 2A, after $1.5 \mathrm{~h}$ there was already a significant increase in the mean fluorescence intensity (MFI) of Cy3 fluorophore in the PC14 cells cultured with astrocyte-22bpCy3 compared to $\mathrm{PC} 14$ cells cultured alone, and this difference gradually increased after $6 \mathrm{~h}$ and $24 \mathrm{~h}$ (mean \pm SEM, $5.3 \pm 1.3,6.9 \pm 2.0$, $9.8 \pm 1.9$ at $1.5 \mathrm{~h}, 6 \mathrm{~h}$, and $24 \mathrm{~h}$ respectively).

To further assess the specificity of the $22 \mathrm{bpCy} 3$ transfer and its contact dependency, we measured the MFI of $\mathrm{Cy} 3$ fluorophore in PC14 cells co-cultured with astrocytes-22bpCy3 for $6 \mathrm{~h}$ using a transwell (contact-independent) or in a mixed co-culture (contactdependent) manner. A representative dot plot of FACS analysis depicting total live-cell gate records is shown in Figure $2 \mathrm{~B}-2 \mathrm{E}$ and quantification of those results in Figure 2H. After $6 \mathrm{~h}$ of co-culturing, the MFI of $\mathrm{Cy} 3$ fluorophore was significantly higher in PC14 cells that were grown in a mixed culture (i.e., in direct contact) with astrocytes-22bpCy 3 than in PC14 cells cultured alone or separated by a transwell membrane from the astrocytes-22bpCy3 (Figure 2H; mean $\pm \mathrm{SEM}, 9.3 \pm 0.9$, $3.3 \pm 0.4$, and $3.5 \pm 0.3$ respectively), indicating that PC14 cells did not acquire the synthetic sRNA when the two cell populations were not in direct contact (Figure 2F-2G). Thus, sRNA transfer was mediated not by secreted particles (such as exosomes), but rather through direct contact between the two cell populations.
To confirm that the synthetic sRNA was transferred from astrocyte cytoplasm, we treated the astrocytes- $22 \mathrm{bpCy} 3$ with RNase A/T to degrade any synthetic sRNA residues that might be attached to astrocyte membranes. Previous studies showed that RNase A/T degrade sRNA [39] although in some sRNA species under some condition e.g., treatment of $\mathrm{pH} 10$, membrane detergent this effect may be partial [46]. As shown in Figure 2F-2G, PC14 cells co-cultured with RNase A/T-treated astrocytes-22bpCy3 acquired a large fraction of the synthetic sRNA, which did not differ significantly from the MFI values of Cy3 fluorophore in the PC14 cells / astrocyte$22 \mathrm{bpCy} 3$ co-cultures that were not treated with RNase $\mathrm{A} / \mathrm{T}$ (Figure $2 \mathrm{H}$; mean $\pm \mathrm{SEM}, 9.3 \pm 0.9$ and $7.8 \pm 2.3$, respectively To further assess the generality of sRNA transfer from astrocytes to cancer cells, we used the same procedure to examine the transfer of $22 \mathrm{bpCy} 3$ from astrocytes to MDA-MB-231 cancer cells. We found that $22 \mathrm{bpCy} 3$ was also transferred from astrocytes-22bpCy3 to MDA-MB-231 cells, and that such transfer was contact dependent (Figure 3).

\section{Transfer of endogenous sRNAs from astrocytes to PC14 cells}

Having demonstrated the transfer of synthetic sRNAs from astrocytes to human PC14 cells, we next wanted to know whether a similar transfer would occur with endogenous sRNAs. PC14 cells were co-cultured with mouse astrocytes in a contact-dependent manner for $6 \mathrm{~h}$, and the PC14 cells (CD340 positive) were then isolated by FACS and total RNA was prepared. Concomitantly, PC14 cells were cultured in the absence of astrocytes or were cocultured with mouse astrocytes in a contact-independent manner (transwell), and RNA was prepared. To identify sRNAs transferred from mouse astrocytes to human PC14 cells, we determined the total sRNA profile by miRNA microarray of the cells used in these three treatments, and identified the transferred mouse astrocytic sRNAs by searching for non-conserved mouse sRNAs in co-cultured human PC14 cells but not in human PC14 cells cultured alone. The miRNA microarray revealed significant differences in 67 sRNA levels in PC14 cells co-cultured with astrocytes for $6 \mathrm{~h}$ in a contact-dependent manner compared to those found in PC14 cells cultured in the absence of astrocytes (fold-change (FC) difference $\geq 1.5$ ). Of those 67 sRNAs, 20 were mouse sRNAs that were up-regulated in the co-cultured PC14 cells (Figure 4A, FC difference $\geq 1.7$ ), indicating that sRNAs were indeed transferred from mouse astrocytes to the human PC14 cells. The transferred sRNAs are listed in Table 1. We confirmed our results by performing quantitative RT-PCR (qPCR, Figure 4B) on selected sRNAs. Notably, miRNA microarray revealed no significant differences in miRNA levels between PC14 cells co-cultured with astrocyte in 
A

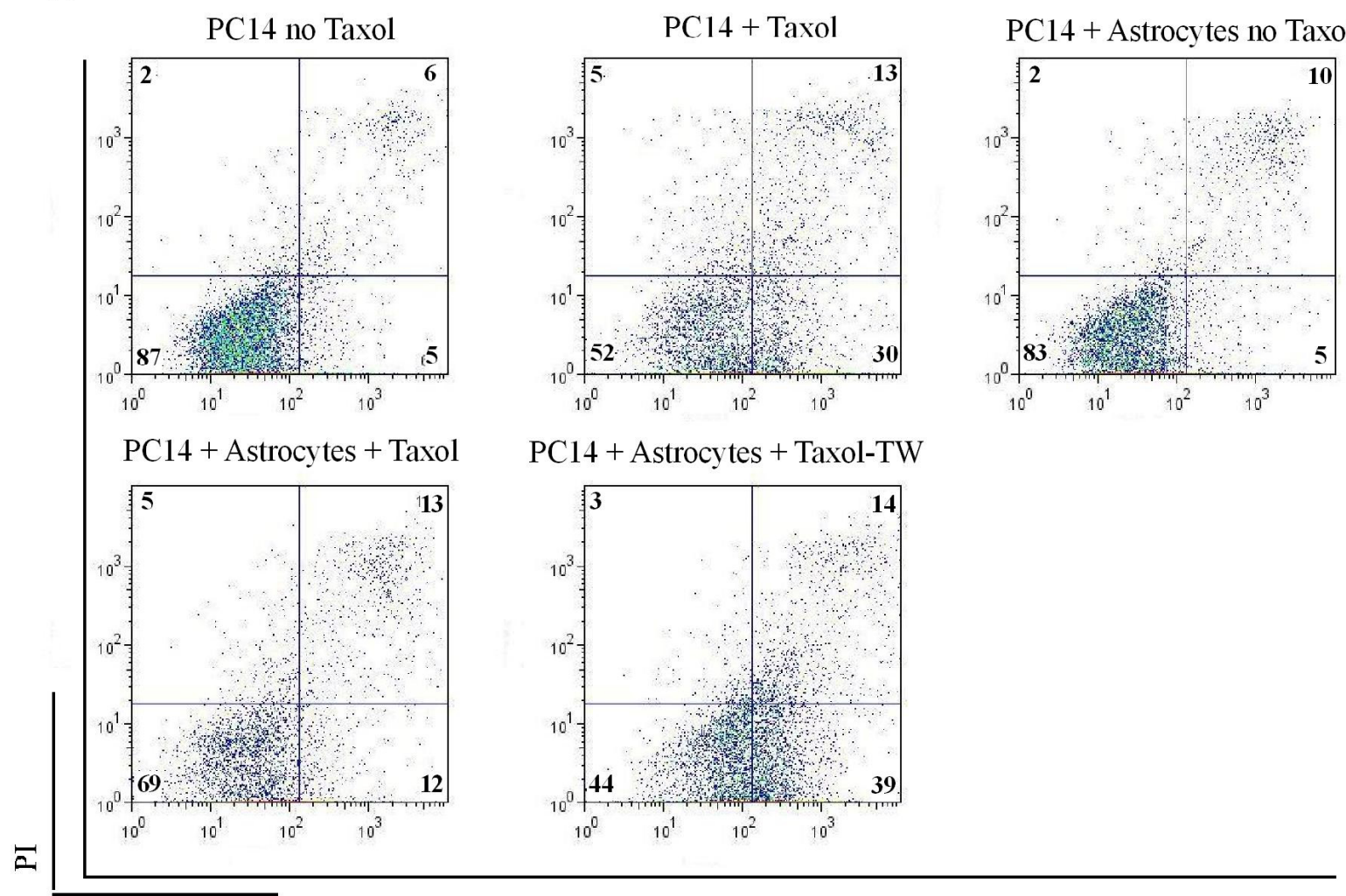

Annexin-V FITS

$\mathrm{B}$

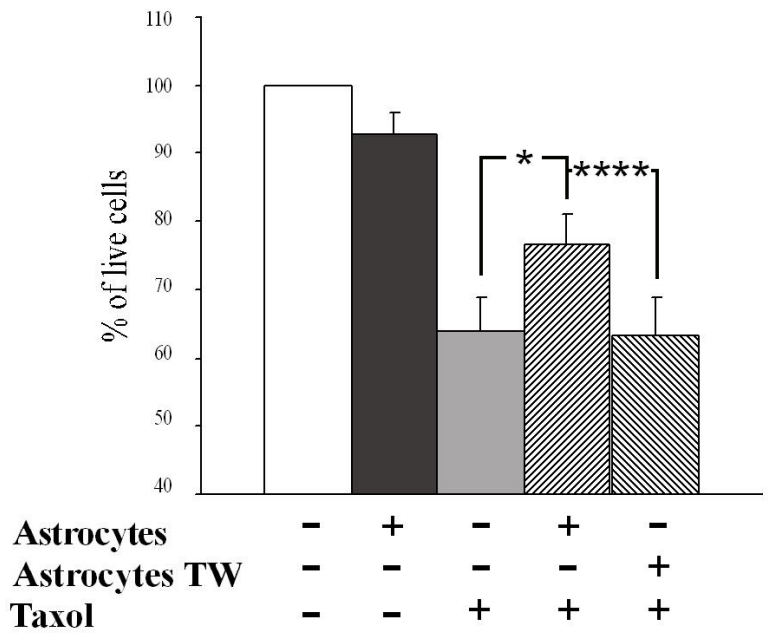

$\mathrm{C}$

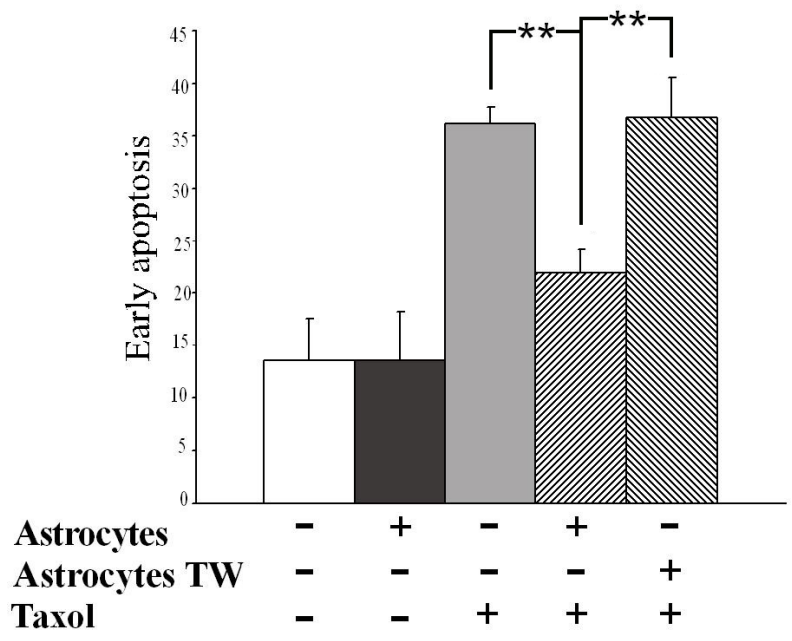

Figure 1: Astrocytes protect PC14 cells from Taxol-induced apoptosis in a contact-dependent manner. The percentages of live and apoptotic cells were determined by FACS analysis (see Materials and Methods section). (A) Representative dot plot of FACS analysis of treated PC14 cells stained with annexin-V FITS and PI. PC14 singlet-cell events are distinguished from target cells by the CD340 specific marker. Numbers in the quadrants are the percentages of PC14 cells within each quadrant. (B, C) Quantitative results of FACS analysis. B. Percentage of live (low PI, low annexin V) PC14 cells cultured alone, with astrocytes, alone plus Taxol, with astrocytes in a contact-dependent manner (mixed co-culture) plus Taxol, and with astrocytes in a contact-independent manner (separated by a transwell membrane (TW)) plus Taxol. Results are expressed as percentages of untreated PC14 cells. C. Apoptotic (high annexin V, low PI) PC14 cells cultured alone, with astrocytes, alone plus Taxol, with astrocytes in a contact-dependent manner plus Taxol, and with astrocytes in a transwell (TW) plus Taxol. The results are expressed as percentage of total cells and are presented as means \pm SEM. Analysis (One-way ANOVA) revealed significant differences in live cell percentages and apoptotic cells between annexin V- stained and PI-stained cells, $P<0.05$. Post-hoc analysis was performed by Fisher's LSD: ${ }^{*} P<0.05,{ }^{* *} P=0.01,{ }^{* * * *} P<0.0001 ; n=4$. 
a contact-independent manner (transwell) and PC14 cells cultured alone (data not shown). We also used qPCR to support our findings that the selected sRNAs were indeed expressed in the mouse astrocytes (data not shown).

\section{Transfer of sRNAs from astrocytes to PC14 cells is mediated by gap junctions}

Having demonstrated the transfer of sRNAs from astrocytes to cancer cells and shown that such transfer requires direct contact between the two cell types, we next examined whether this transfer is mediated via gap-junction communication. PC14 cells and astrocytes-22bpCy3

$\mathbf{A}$
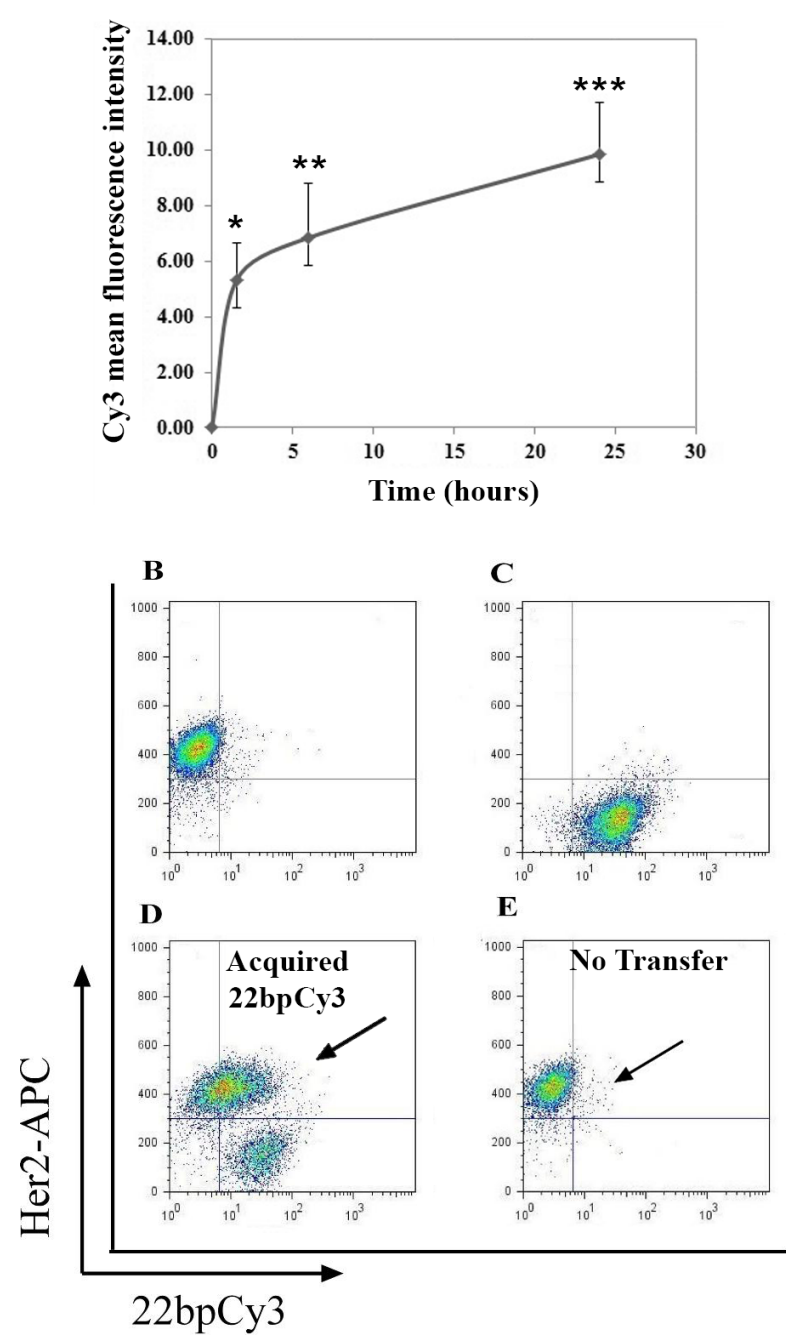

were each pretreated for $16 \mathrm{~h}$ with different concentrations (50-150 $\mu \mathrm{M})$ of Carbenoxolone (CBX), a well-known gap-junction inhibitor. The cells were then co-cultured for $6 \mathrm{~h}$ in the continuing presence of CBX. After treatment with $50 \mu \mathrm{M}$ or $150 \mu \mathrm{M}$ CBX, FACS analysis (Figure $5 \mathrm{~A}$ ) revealed a significant decrease in the MFI of $\mathrm{Cy} 3$ fluorophore in the PC14 cells (29\% and 35\%, respectively) compared to untreated cells (Figure 5B). These results indicated that $\mathrm{CBX}$ inhibits transfer of the Cy3-labeled synthetic sRNA from astrocytes-22bpCy3 to PC14 cells.

Next, we examined the effect of CBX on the transfer of endogenous sRNAs from astrocytes to PC14 cells. The sRNAs chosen for this analysis were
$\mathbf{F}$

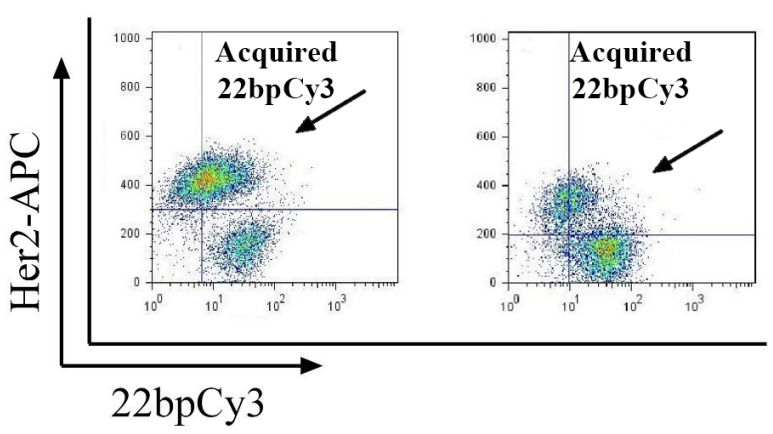

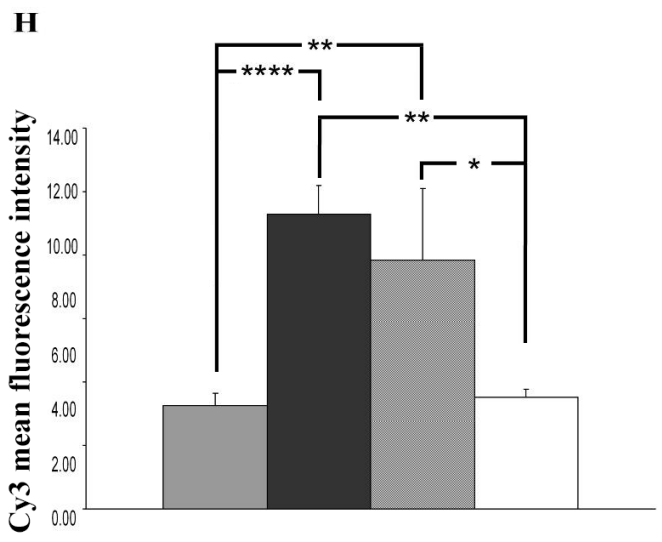

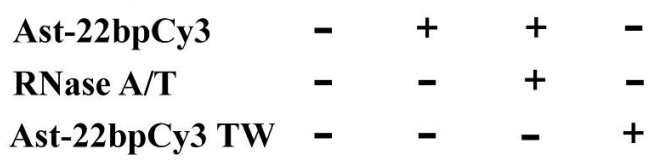

Figure 2: Cy3-tagged 22-bp oligonucleotides are transferred from astrocytes to PC14 cells. PC14 cells (CD340 positive) containing $22 \mathrm{bpCy} 3$ were assayed by FACS analysis (see Materials and Methods section). (A) Time course of $22 \mathrm{bpCy} 3$ transfer from astrocytes to PC14 cells. B-G. Representative dot plots of the results of FACS analysis after the different treatments, depicting total live-cell gate records. (B) PC14 cells (CD340 positive) alone. (C) 22bpCy3-transfected astrocytes (Cy3 positive) alone; positive for Cy3. D, E. PC14 cells co-cultured with astrocytes-22bpCy3 in a contact-dependent (D) or contact-independent (transwell, TW) manner (E) F, G. Astrocytes-22bpCy3 were co-cultured with PC14 cells that were untreated (control) (F) or treated with RNase A/T (G) (H) Quantitative results of FACS analysis, expressed as mean fluorescence intensity (MFI) of 22bpCy3 recorded in the PC14 cells and presented as means \pm SEM. Analysis (One-way ANOVA) revealed significant differences in MFI of 22bpCy3 between the groups: $P<0.05$. Post-hoc analysis by Fisher's LSD yielded $* P<0.05, * * P<0.01, * * * * P<0.0001 ; n=5$. 
mmu-miR-16*, mmu-miR-709, mmu-miR-1195 and endo-siRNA-1196, all shown on microarray analysis to exhibit marked differences in fold change, and whose reported gene targets may have relevant protective activity, for example in connection with apoptosis, cell cycle, and p53-signaling pathways (Qiagen's Ingenuity ${ }^{\circledR}$ Pathway Analysis). Astrocytes and PC14-GFP cells were pretreated with $50 \mu \mathrm{M}$ or $150 \mu \mathrm{M} \mathrm{CBX}$ for $16 \mathrm{~h}$, and were then co-cultured for $6 \mathrm{~h}$ in the continuing presence of CBX, after which PC14 cells (GFP-positive) were isolated by FACS and their total RNA was prepared. Levels of mmu-miR-16*, mmu-miR-709, mmu-miR-1195 and endo-siRNA-1196 were assayed by qPCR. sRNA levels were not affected by treatment with $50 \mu \mathrm{M}$ CBX However, treatment with $150 \mu \mathrm{M}$ CBX significantly decreased mmu-miR-16* levels by $80 \%$, mmu-miR-709 levels by $70 \%$, mmu-miR-1195 levels by $82 \%$, and endo-siRNA-1196 levels by $78 \%$

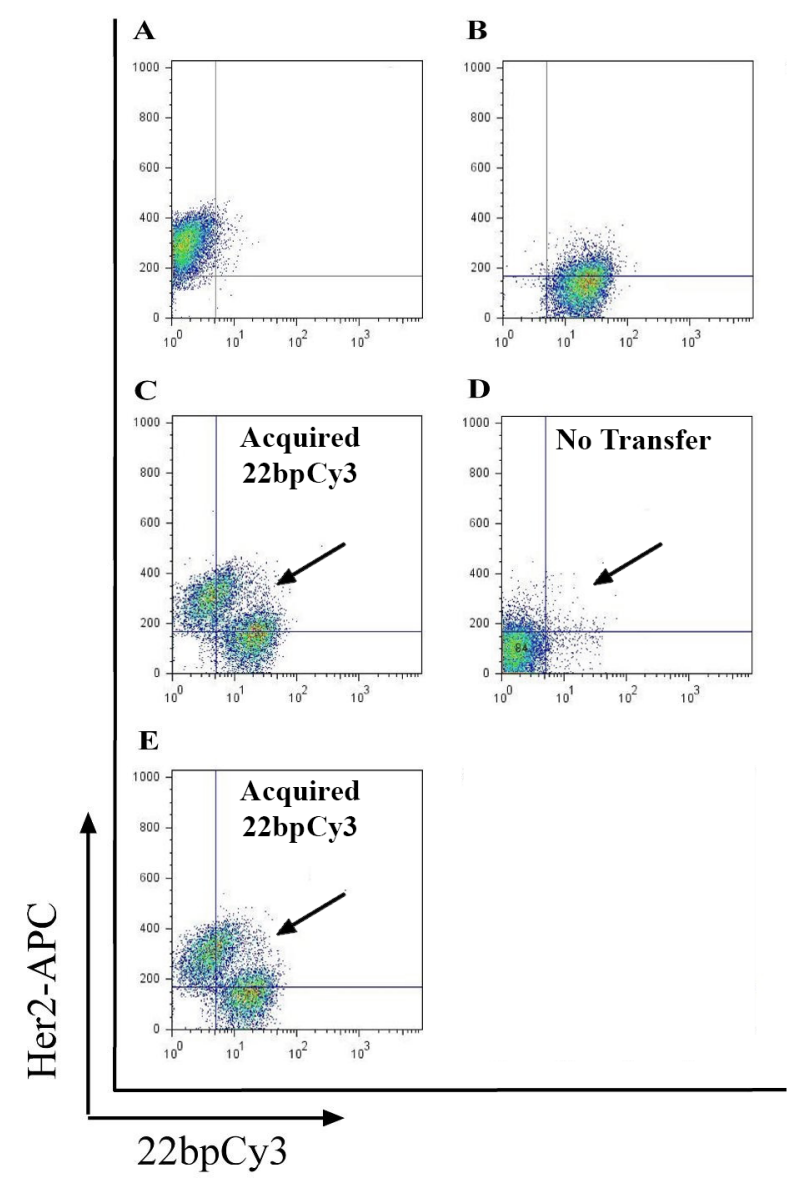

compared to CBX-untreated cells (Figure 5C-5F). These findings suggested that the transfer of sRNAs from astrocytes to PC14 cells is mediated by gap-junction communication.

\section{Combined enforced expression of miR-709 with two other sRNAs protects PC14 cells from Taxol toxicity}

To further support the notion that sRNAs transferred from astrocytes promote a protective effect of astrocytes against chemotherapy, we next examined whether the transferred sRNAs identified here showed the potential for promoting a protective effect against Taxol in PC14 cells. To this end we exogenously expressed mmu-miR-16*, mmu-miR-709, mmu-miR-1195 and endo-siRNA-1196 sRNAs in PC14 cells. The mmu-miR-16*, mmu-miR-1195, and endo-siRNA-1196 were expressed in the PC14 cells

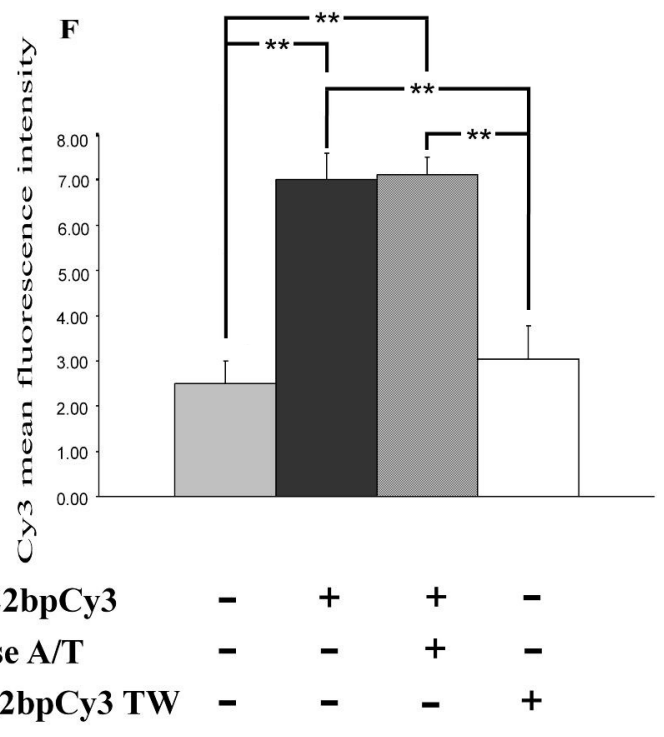

Figure 3: Cy3-tagged 22-bp oligonucleotides are transferred from astrocytes to MDA-MB-231 cells. Astrocytes-22bpCy3 were co-cultured with MDA-MB-231 cells for $6 \mathrm{~h}$. MDA-MB-231 cells (CD340 positive) containing 22bpCy3 were assayed by FACS analysis (see Materials and Methods section). (A-E) Representative dot plots of the results of FACS analysis after the different treatments, depicting total live-cell gate records A. MDA-MB-231 cells (positive for CD340) alone. B. 22bpCy3-transfected astrocytes (Cy3-positive) alone. C, D. MDA-MB-231 cells co-cultured with astrocytes-22bpCy3 in a contact-dependent (C) or contact-independent (transwell, TW) manner (D). E. MDA-MB-231 cells co-cultured with astrocytes-22bpCy3 treated with RNase A/T. (F) Quantitative results of the FACS analysis, expressed as MFI of $22 \mathrm{bpCy} 3$ recorded in the MDA-MB-231 cells and presented as means \pm SEM. Analysis (One-way ANOVA) revealed significant differences in MFI of 22 bpCy3 between the groups: $P<0.01$. Post-hoc analysis by Fisher's LSD yielded $* * P<0.01 ; n=5$. 
Table 1: List of non-conserved mouse sRNAs found in co-cultured PC14 cells

\begin{tabular}{|c|c|c|}
\hline Small RNA & $P$ value & Fold change \\
\hline mmu-miR-2134 & $7.42 \mathrm{E}-05$ & 44.7597 \\
\hline mmu-miR-1196 & 0.00671439 & 16.8571 \\
\hline mmu-miR-1195 & 0.00105692 & 15.1575 \\
\hline mmu-miR-709 & 0.00259631 & 12.3438 \\
\hline mmu-miR-1894-5p & 0.0001579 & 6.08979 \\
\hline mmu-miR-1946a & 0.00733713 & 5.59805 \\
\hline mmu-miR-714 & 0.000206816 & 3.95919 \\
\hline mmu-miR-1962 & $7.80 \mathrm{E}-06$ & 3.33373 \\
\hline mmu-miR-1937b & 0.000172545 & 2.95365 \\
\hline mmu-miR-1937a & 0.000784034 & 2.83139 \\
\hline mmu-miR-1187 & 0.0325853 & 2.74294 \\
\hline mmu-miR-16-star & 0.0190219 & 2.46428 \\
\hline mmu-miR-2132 & 0.029467 & 2.42419 \\
\hline mmu-miR-669c & 0.0155178 & 2.21774 \\
\hline mmu-miR-466j & 0.026805 & 2.16929 \\
\hline mmu-miR-466c-5p & 0.0241965 & 1.98764 \\
\hline hp_mmu-mir-346 & 0.0142571 & 1.83521 \\
\hline mmu-let-7d-star & 0.00304475 & 1.80533 \\
\hline mmu-miR-466f-3p & 0.0337132 & 1.7063 \\
\hline mmu-miR-1946b & 0.0323624 & 1.70281 \\
\hline
\end{tabular}

The miRNA microarray reveals a significant increase in levels of 20 sRNAs in PC14 cells co-cultured for $6 \mathrm{~h}$ with astrocytes in a contact-dependent manner (mixed cultures) compared to PC14 cells cultured for $6 \mathrm{~h}$ in the absence of astrocytes $(P<0.05$ by $t$-test: fold-change (FC) difference $\geq 1.7$ ).

via the miR-Vec miRNA-expressing system [47] and mmu-miR-709 was expressed via miRNA mimic. PC14 cells were transiently transfected with each of these sRNAs or with their combinations, and $24 \mathrm{~h}$ later the transfected cells were treated with Taxol $(25 \mathrm{nM})$ for $48 \mathrm{~h}$ and their viability was examined by the MTT assay. As a control, PC14 cells were transfected with a mimic negative control, empty miR-Vec plasmid, or both. Transfection with one sRNA or with two sRNAs did not increase cell viability compared to control (Figure 6A-6B). However, transfection with miR-709 plus two sRNAs, or transfection with all four sRNAs (miR-16* + miR-709+ miR-1195, miR-16* + miR-709 + endo-siRNA-1196, miR-709 + miR-1195 + endo-siRNA-1196, and miR-16* + miR-709 + miR-1195+ endo-siRNA-1196), significantly increased cell viability compared to controls (mean $\pm \mathrm{SEM}, 86 \% \pm$ $11 \%, 90 \% \pm 6.9 \%, 87 \% \pm 8 \%, 88.6 \% \pm 4.5 \%$, and $66.7 \%$ $\pm 5.8 \%$ respectively; Figure $6 \mathrm{C}$ ). Transfection with miR$16^{*}+$ miR-1195+ endo-siRNA-1196 did not protect PC14 cells relative to control $(76.7 \% \pm 6.5 \%$ and $66.7 \% \pm 5.8 \%$ respectively; Figure 6C). Taken together, these results suggest that enforced expression of miR-709 combined with two other sRNAs can promote a protective effect against Taxol toxicity in PC14 cells.

\section{DISCUSSION}

The aim of this study was to examine the possibility that the transfer of sRNAs from astrocytes to metastatic tumor cells underlies the mechanism whereby astrocytes protect brain metastatic tumors from the toxicity of chemotherapy. We focused on the transfer of sRNAs from astrocytes to PC14 cells, a cell line of aggressive human lung adenocarcinoma, and to MDA-MB-231, an aggressive human breast adenocarcinoma cell line. Both cell lines are known to metastasize to the brain $[19,48]$. Our results showed that sRNAs are indeed transferred from astrocytes to these cancer cells, that the transfer is contact-dependent and most probably occurs through gap junctions, and that the combined expression of selected transferred sRNAs in PC14 cells was found to increases their resistance to chemotherapy. Collectively, these results suggested that astrocytes protect brain metastatic cancer cells from chemotherapy by transferring sRNAs to the cancer cells, where they promote protective activity. Previous studies have also shown that astrocytes promote cancer cell protection $[18,19]$. However, whether the transferred sRNAs regulate the processes by which astrocytes protect tumor cells from chemotherapy, or act 
A

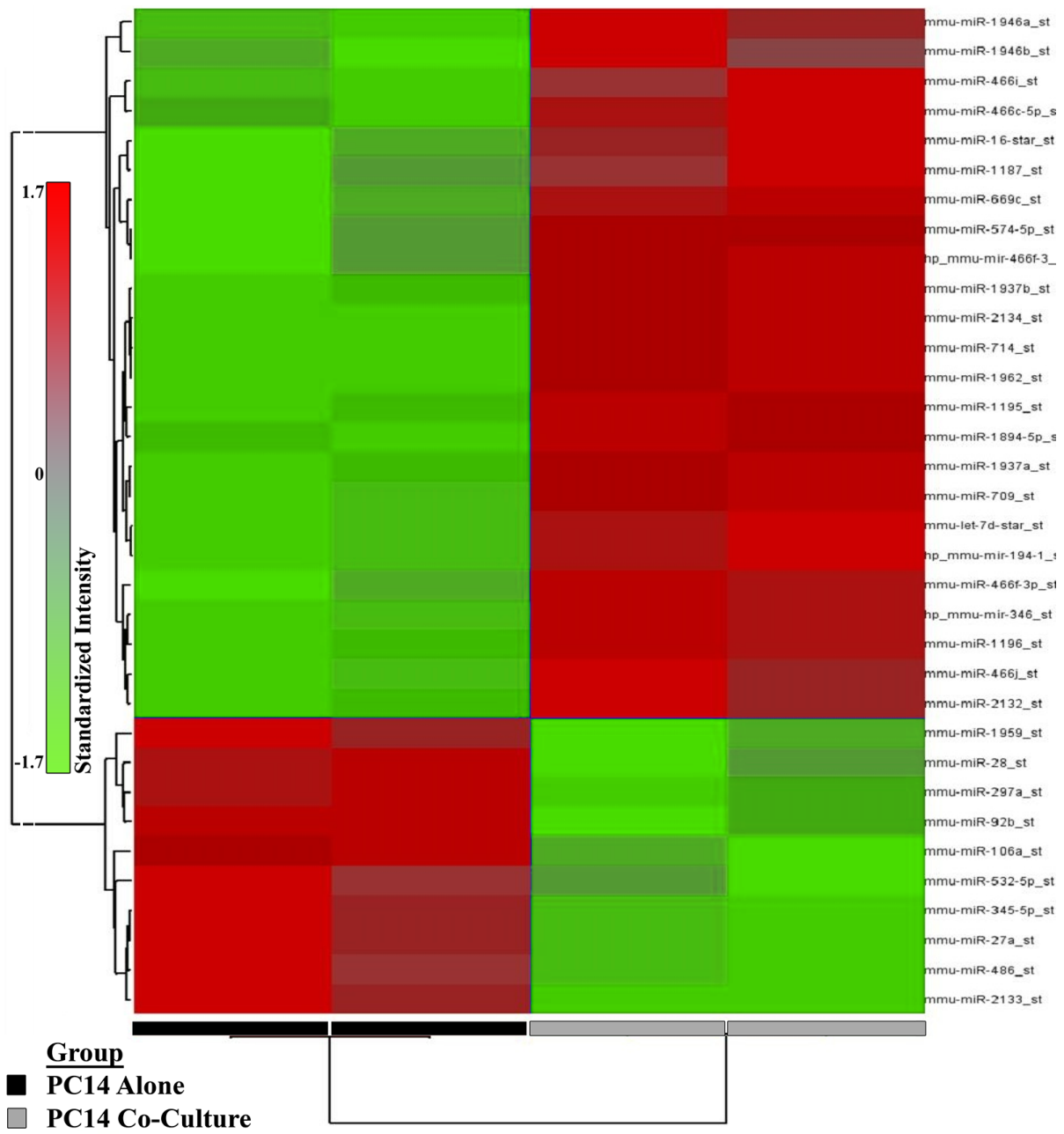

$\mathrm{B}$

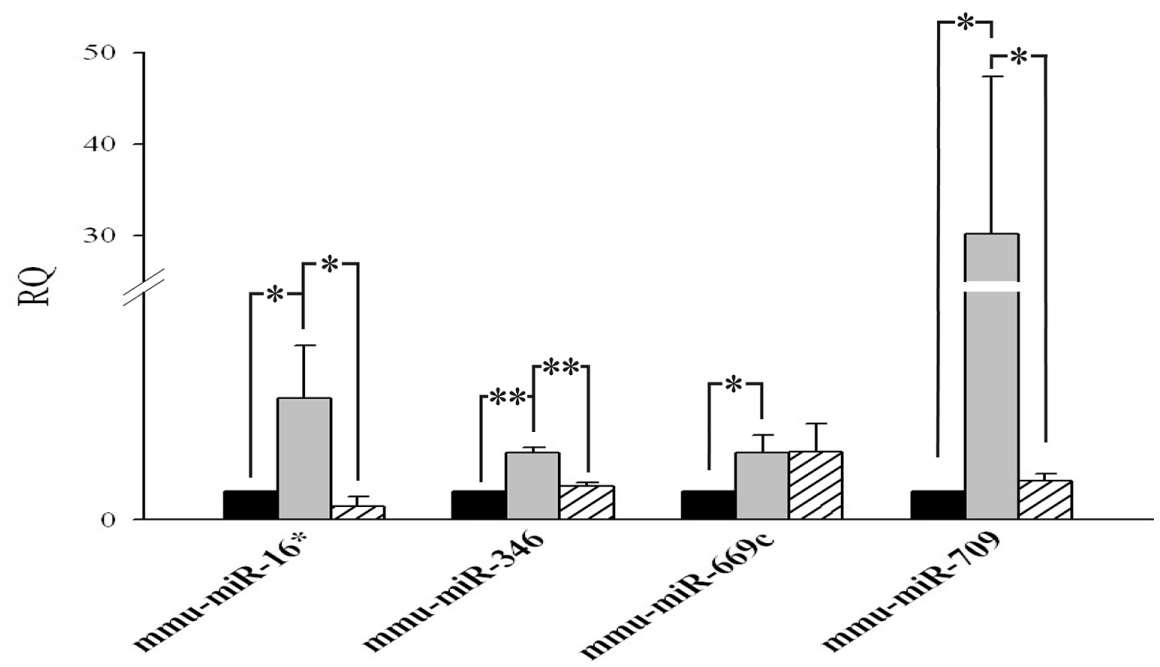

Figure 4: Small RNAs are transferred from astrocytes to PC14 cells. Levels of mouse-specific sRNA in PC14 cells cultured alone were compared with the levels in PC14 cells co-cultured with astrocytes in the mixed co-cultures. (A) Heat map of miRNA microarray (two independent experiments for each treatment). Mouse-specific sRNAs $(n=20)$ whose expression was higher in PC14 cells co-cultured with astrocytes than in PC14 cells cultured alone are depicted. (B) Microarray results were confirmed by qPCR of the indicated miRNAs (see Materials and Methods section). Black bar, PC14 cultured alone; grey bar, PC14 cells co-cultured with astrocytes in a contact-dependent manner; striped bar, PC14 cells co-cultured with astrocytes in a contact-independent manner (transwell, TW). Results are presented as means \pm SEM. Analysis (One-way ANOVA) revealed significant differences in sRNA expression between the groups: $P<0.05$. Post-hoc analysis by Fisher's LSD yielded $* P<0.05, * * P<0.01 ; n=3$; mmu, Mus musculus. 
independently of them, is not yet known. To examine the possibility that the transferred sRNAs protect the cancer cells from chemotherapy, we focused on four sRNAs (mmu-miR-16*, mmu-miR-709, mmu-miR-1195, and endo-siRNA-1196), all found here to be transferred from astrocytes to PC14 cells. These sRNAs were chosen because microarray analysis showed that their amounts in the tumor cells were high relative to the other transferred sRNAs, and also because their reported gene targets may be of relevance for a protective role, for example in apoptosis, in cell cycle, or in p53 signaling. We found that enforced expression with one or two sRNAs did not suffice to increase cell viability, but that enforced expression with miR-709 in combination with two other sRNAs was
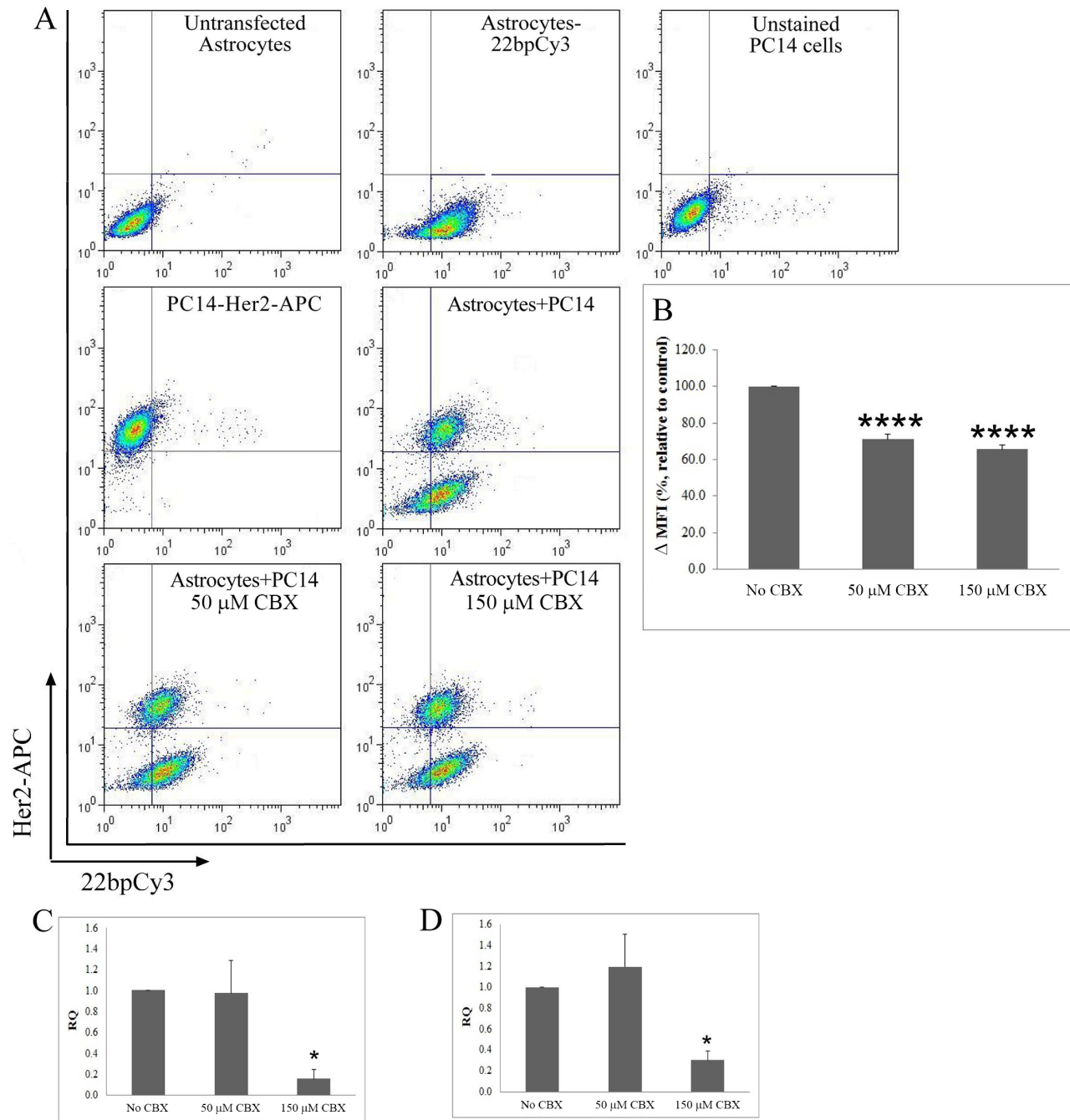

$\mathrm{E}$
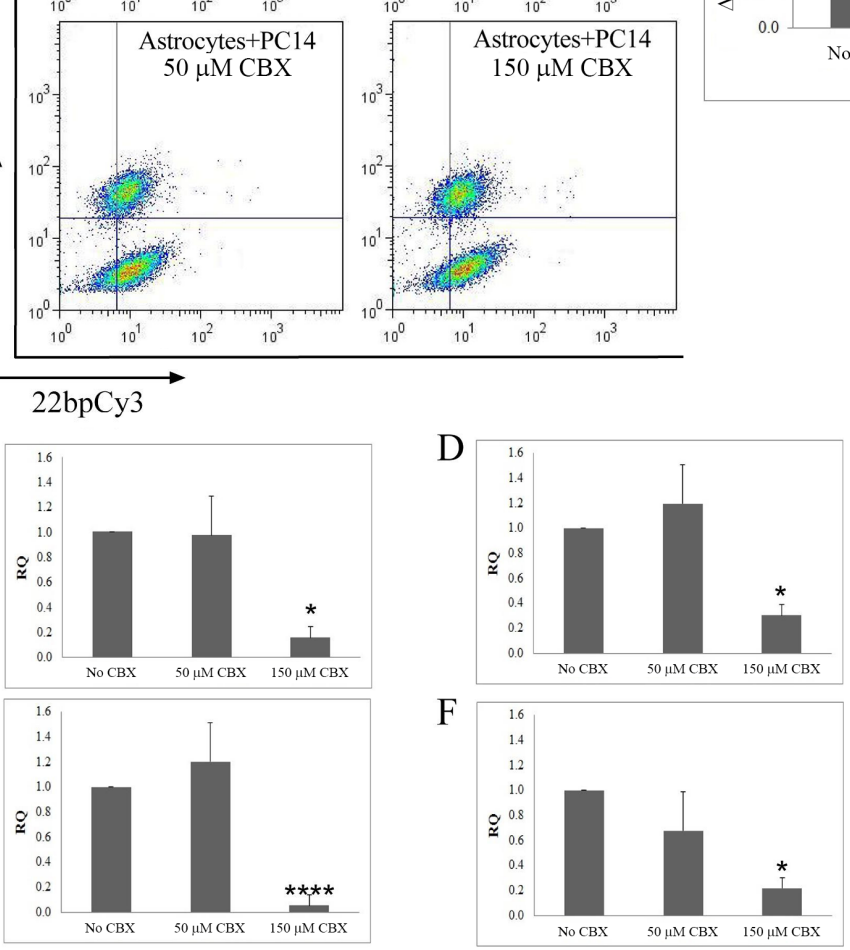

Figure 5: Inhibition of gap-junction communication and analysis of intercellular transfer of endogenous sRNAs. (A, B) The gap-junction inhibitor CBX inhibits transfer of $22 \mathrm{bpCy} 3$ from astrocytes to PC14 cells. PC14 cells (CD340 positive) containing $22 \mathrm{bpCy} 3$ were assayed by FACS analysis (see Materials and Methods section). A. Representative dot plots of the results of FACS analysis after the different treatments, depicting total live-cell gate records. B. Quantitative results of FACS analysis expressed as MFI of $22 \mathrm{bpCy} 3$ recorded in PC14 cells cultured with astrocytes-22bpCy3 that were treated with $\mathrm{CBX}(50 \mu \mathrm{M} / 150 \mu \mathrm{M})$ or untreated (control). CBX inhibited the transfer of endogenous sRNA from the astrocytes to the PC14 cells. C-F. Levels of mmu-miR-16* (C), mmu-miR-709 (D), mmu-miR-1195 (E) and endo-siRNA-1196 (F) were measured in PC14-GFP cells by qPCR (see Materials and Methods section). Results are presented as means \pm SEM. Analysis (One-way ANOVA revealed significant differences in MFI of 22 bpCy3 between the groups: $P<0.05$. Post-hoc analysis by Fisher's LSD yielded $* P<0.05, * * * * P<0.0001 ; n=4$. 
sufficient to induce the protective effect, suggesting that this miRNA might play an important role in the protective effect mediated by the astrocytes. These results are in line with previous results suggesting that miR-709 can act as an oncomiR [49-51]. Thus, in hepatocellular carcinoma miR-709 is up-regulated and promotes proliferation, migration, and invasion by targeting glypican-5 (GPC5), a tumor suppressor protein that is highly expressed in lung adenocarcinoma tissue relative to its expression in normal lung tissue $[49,52]$. In addition, miR-709 has been shown to regulate the biogenesis of miR-15a and miR-16-1 through suppression of pre-miR-15a/16-1 maturation, suggesting a role for miR-709 in the regulation of apoptosis through the miR-16/Bcl 2 pathway [51]. Moreover, DNA damage in germ cells up-regulates miR-709 expression, which in turn targets the mRNA

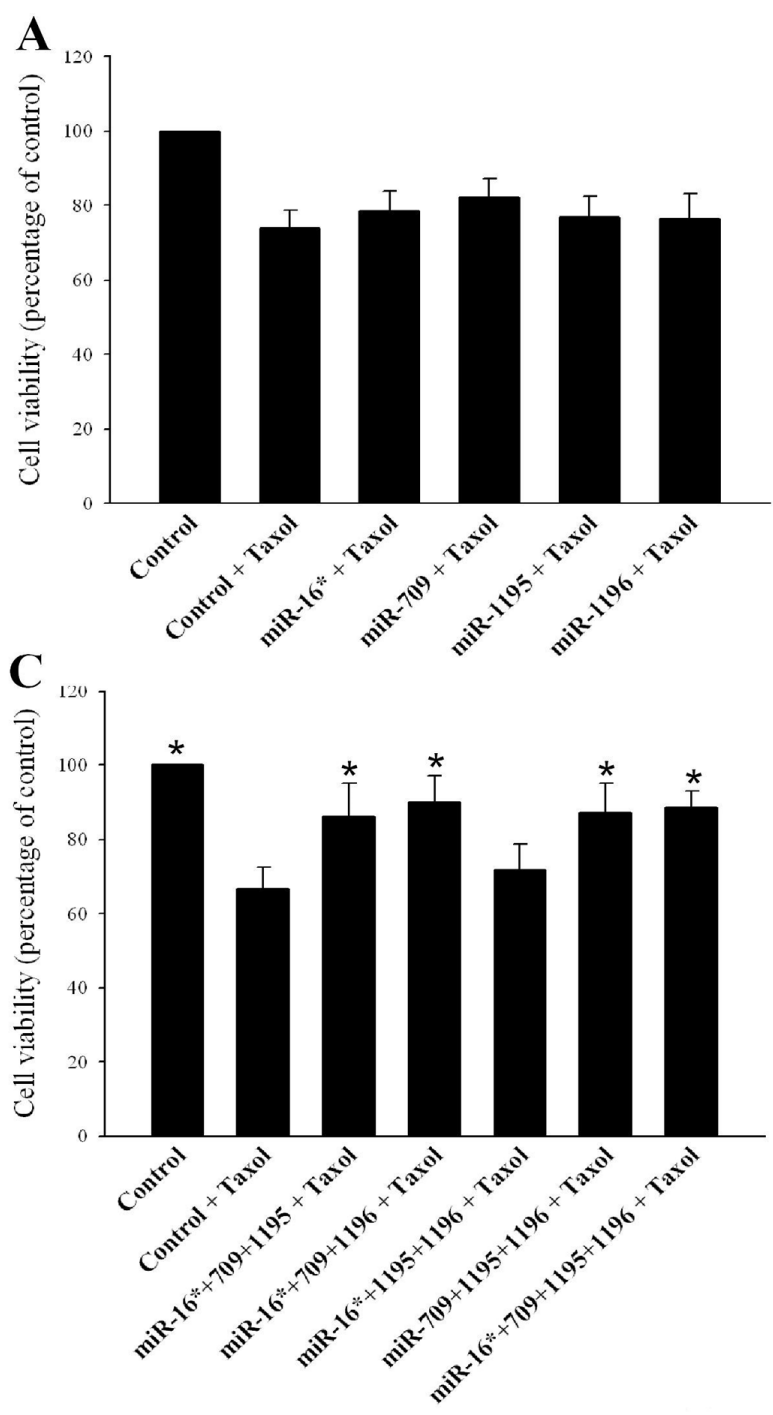

of BORIS (brother of the regulator of imprinted sites) to counteract aberrant DNA hypomethylation [50]. Another study showed that miR-709 acts as a suppressor of oncogenesis. Reduced levels of miR-709 are required for the initiation and maintenance of human $\mathrm{T}$ cell acute lymphoblastic leukemia [53]. Our results showed that mmu-miR-1195, endo-siRNA-1196 and mmu-miR-16* may also contribute to the protective effect, although only when administered in combination with miR-709. miR1195 is regulated by the NK2 homeobox 1 (NKX2-1) [54]. NKX2-1 has both oncogenic and tumor-suppressor functions depending on the cell context [55]. In lung cancers, NKX2-1 is amplified and may participate in the pulmonary tumorigenic process [56]. sRNA-1196 is a DICER-dependent and DGCR8-independent sRNA that was recently reclassified as an endo-siRNA [57].

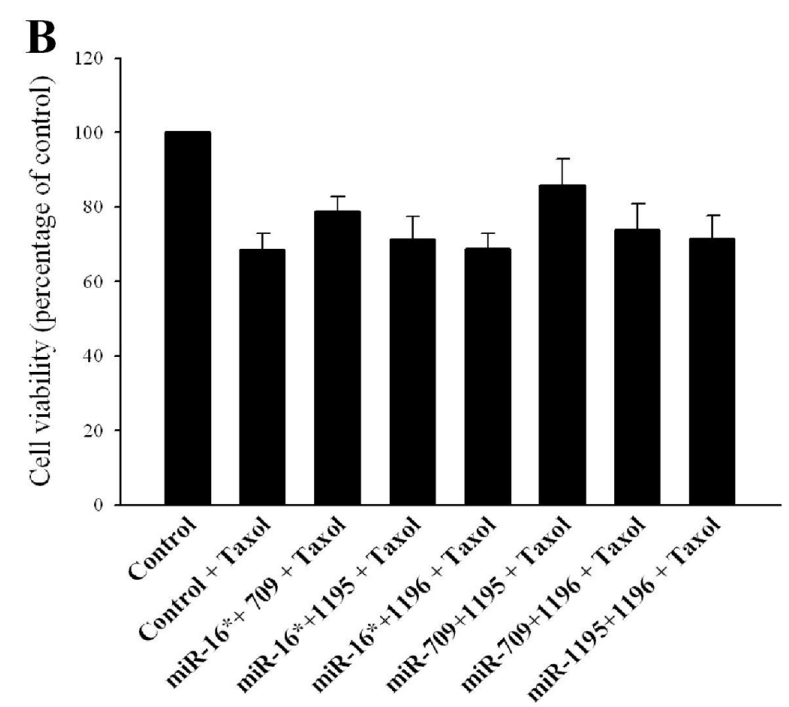

Figure 6: Combined enforced expression of miR-709 with two other sRNAs protects PC14 cells from Taxol-induced toxicity. (A, B) Transfection with one or two sRNAs did not increase cell viability compared with control cells transfected with either mimic negative control or empty miR-Vec plasmid or both. (C) Transfection with miRNA-709 in combination with two sRNAs or all four sRNAs significantly increased cell viability compared to controls. Results are presented as means \pm SEM. Analysis (One-way ANOVA) revealed significant differences between the groups: $P<0.05$. Post-hoc analysis by Fisher's LSD yielded $* P<0.05 ; v v=5$. 
Endo-siRNAs are a class of small RNAs generated by the sequential cleavage of the endonuclease DICER, independently of DROSHA, of long double-stranded RNA molecules. A role for endo-siRNAs has been documented in several biological systems, such as development and stress response [58]. Their role in cancer, however, remains largely unknown. With respect to miR-16*, precursor miRNAs are processed in the cytoplasm by the endonuclease DICER, producing a mature miRNA and a passenger strand. The mature miRNA that regulates gene expression is the guide strand (miR-\#-5p). The passenger strand (miR-\#-3p/ miRNA*) is believed to be degraded and inactivated [59]. Accumulating evidence suggests, however, that the miRNA* strand can regulate gene expression [60]. In prostate cancer cells, for example, miR-17-3p functions as an oncogene [60]. The human genome does not contain obvious homologues of miR-16*, miR-1195 and Endo-siRNA-1196; it does, however, contain target sequences of these sRNAs in some of their 3'UTR mRNAs. miR-709 is an exception in that its seed is identical to that of the human miR-1827. miR-1195 is also partially homologous with the human miRNA hsa-miR-584-3p.

We found that the mechanism whereby sRNAs are transferred from astrocytes to PC14 cells involves direct interaction between the cells, and that the sRNAs are probably transferred via gap junctions between the two cell types. The need for direct cell-cell contact was shown by the fact that transfer of $22 \mathrm{bpCy} 3$ from astrocytes to PC14 cells was not detectable when donor and acceptor cells were separated by a transwell membrane. Further support came from the miRNA microarray analysis, since we could not detect the presence of mouse-derived sRNAs in PC14 cells co-cultured with astrocytes in the transwell experiment. We examined the possibility of transfer via gap junctions by assessing the effect of CBX, a well-known gap-junction antagonist on the sRNA transfer. CBX is a glycyrrhetinic acid derivative with a steroid-like structure that has diverse pharmacological activities. It influences endogenous glucocorticoids and has been used to treat peptic, esophageal and oral ulceration, and inflammation. The principal side effects of $\mathrm{CBX}$ are sodium retention with suppression of the renin-angiotensin-aldosterone system [61]. CBX is also known as a modestly potent, water-soluble blocker of gap junctions $[62,63]$. We cannot exclude the possibility that CBX act on the sRNAs transfer by other mechanism(s) besides affecting gap junction. However, since numerous studies have shown that CBX affects gap junctions, [17-19, 64-67] we favor more the possibility that its effect is mediated via the gap-junction. CBX significantly reduced the transfer of $22 \mathrm{bpCy} 3$ as well as of mmumiR-709, mmu-miR-1195, endo-siRNA-1196, and mmumiR-16*. Notably, CBX was more effective in inhibiting the transfer of the endogenous sRNAs than $22 \mathrm{bpCy} 3$. One possible explanation for this difference is that the concentration of $22 \mathrm{bpCy} 3$ in the transfected astrocytes is much higher than endogenous sRNAs and therefore higher concentration of $\mathrm{CBX}$ is required to inhibit its transfer compared to the concentration needed to inhibit the transfer of endogenous sRNAs. Another potential explanation is that $22 \mathrm{bpCy} 3$ might be transferred from astrocytes to tumor cells via additional mechanisms besides gap junctions. Nonetheless, these results strongly suggested that sRNAs are transferred from astrocytes to cancer cells via gap junctions. This assumption is further supported by our finding that both astrocytes and PC14 cells expressed gap junction proteins (data not shown). These findings are in line with a previous study showing that inhibition by $\mathrm{CBX}$ of the protective effect of astrocytes co-cultured with Taxol-treated cancer cells is mediated by gap junctions [18].

Altogether, our results suggest that cell-to-cell transfer of sRNAs from astrocytes to tumor cells serves as a mechanism for promoting the resistance of brain metastatic tumors to chemotherapy. These findings may therefore lead to the development of promising new therapeutic approaches that target such transfer for the treatment of patients with brain metastases.

\section{MATERIALS AND METHODS}

\section{Cell cultures and reagents}

Human lung adenocarcinoma cell line PC14 [19, 48] and human breast adenocarcinoma cell line MDAMB-231 were maintained as monolayer cultures as described in detail elsewhere [19] at $37^{\circ} \mathrm{C}$ in a humidified $5 \% \mathrm{CO}_{2}$ incubator. Conditioned immortalized mouse astrocytes were isolated from neonatal mice homozygous for a temperature-sensitive SV40 large tumor (T) antigen (H-2Kb-tsA58 mice; CBA/Ca $\times$ C57Bl/10 hybrid; Charles River Laboratories) and established in culture as described in detail elsewhere [45]. Cells were maintained at $33^{\circ} \mathrm{C}$ in a humidified $8 \% \mathrm{CO}_{2}$ incubator.

\section{Chemoprotection experiments}

PC14 cells were cultured with astrocytes at a 1:1 ratio and treated with Taxol ( $5 \mathrm{nM}$ ) for $48 \mathrm{~h}$. The cells were then trypsinized, washed once with PBS and resuspended in PBS (100 ul). PC14 was immunofluorescently stained with APC anti-human CD340 (erbB2/HER2) Antibody (Ab; Biolegend), for $15 \mathrm{~min}$ at room temperature (RT). To assess chemoprotection, the percentages of live cells and apoptotic cells were quantified.

\section{Apoptosis assay}

To measure apoptosis we used the $\mathrm{MEBCYTO}^{\circledR}$ Apoptosis Kit (annexin V-fluorescein isothiocyanate 
(FITC) and propidium iodide (PI); MBL International) according to the manufacturer's instructions. Percentages of live and apoptotic cells were measured by flow cytometry using a single laser-emitting excitation light at $488 \mathrm{~nm}$. PC14 singlet-cell events were distinguished from target cells by their APC anti-human CD340 specific marker. APC signal was detected by excitation with a 633 $\mathrm{nm}$ laser through a 660/20 bandpass filter. Data collected from $\sim 10,000$ single-cell events were analyzed.

\section{Synthetic small RNA transfection}

Astrocytes $\left(2.5 \times 10^{5}, 6\right.$-well tissue culture plate) were transfected with $\mathrm{Cy}^{\mathrm{TM}} 3$ dye-labeled Pre-miR ${ }^{\mathrm{TM}}$ Negative Control \#1 (22bpCy3, Ambion) using TransITsiQUEST Transfection Reagent (Mirus), according to the manufacturer's instructions. A complex of TransITsiQUEST $(6 \mu \mathrm{l})$ and $\mathrm{Cy}^{\mathrm{TM}}$-labeled-miR $(1 \mu \mathrm{l}, 50 \mu \mathrm{M})$ was diluted in $250 \mu \mathrm{l}$ Opti-MEM I Reduced-Serum Medium and dripped gently onto the astrocytes.

\section{Co-cultures and analysis of intercellular transfer of synthetic sRNA by FACS}

For intercellular transfer of synthetic sRNA we used $22 \mathrm{bpCy} 3$ as a transfer marker. Donor astrocytes were transfected with $22 \mathrm{bpCy} 3$ as described above, and $24 \mathrm{~h}$ after transfection the cells were thoroughly washed to remove surplus $22 \mathrm{bpCy} 3$ left from the original transfection prior to co-culturing. Cells of the PC14 or MDA-MB-231 cell line $\left(4 \times 10^{5}\right)$ were added to the $22 \mathrm{bpCy} 3$-transfected astrocytes (hereafter 'astrocytes-22bpCy3') to obtain a 1:1 effector:target ratio and were co-cultured at $37^{\circ} \mathrm{C}$ in a humidified $5 \% \mathrm{CO}_{2}$ incubator for $6 \mathrm{~h}$. For FACS-based analysis of $22 \mathrm{bpCy} 3$ transfer, the cells were trypsinized, washed once with PBS, and resuspended vigorously in $5 \mathrm{mM}$ EDTA/PBS. PC14 or MDA-MB-231 cells were immunofluorescently stained with APC anti-human CD340 Ab as described above. After labeling the cells were washed with PBS and again resuspended in $5 \mathrm{mM}$ PBS/EDTA. Transfer of the synthetic sRNA from astrocytes to PC14 cells was analyzed by FACS.

\section{FACS analysis}

For multi-parametric FACS analysis, cell samples were analyzed on a FACSCalibur ${ }^{\mathrm{TM}}$ using Cellquest ${ }^{\mathrm{TM}}$ software or on a FACSAria ${ }^{\mathrm{TM}}$ instrument using FACSDiva $^{\mathrm{TM}}$ software (all from BD Biosciences). Data collected from $\sim 10,000$ single-cell events were analyzed. PC14 singlet-cell events were distinguished from target cells by their APC anti-human CD340 specific marker. The Cy3 signal was detected by excitation with a 561 laser through a 582/15 bandpass filter, and the APC signal by excitation with a 633 laser through a 660/20 bandpass filter. An increase in mean fluorescence intensity
(MFI, log mode) of $22 \mathrm{bpCy} 3$ recorded in PC14 cells co-cultured with astrocytes relative to $\mathrm{PC} 14$ cells cultured alone was used to evaluate the intercellular transfer of the synthetic small RNA. Final data analysis was performed with FlowJo software (Ashland).

\section{Time-course assay}

To examine the transfer time course of the tagged synthetic sRNA, PC14 cells $\left(4 \times 10^{5}\right)$ were co-cultured with astrocytes-22bpCy3 $\left(2.5 \times 10^{5}\right)$ in a 6-well plate at $37^{\circ} \mathrm{C}$, for $1.5 \mathrm{~h}, 6 \mathrm{~h}$, or $24 \mathrm{~h}$. At the end of the co-culturing the PC14 cells were stained with APC anti-human CD340 $\mathrm{Ab}$ to label PC14 cells, and analyzed for $22 \mathrm{bpCy} 3$ acquisition by FACS as described above.

\section{RNase A/T1 treatment}

To confirm that the synthetic sRNA was transferred from astrocyte cytoplasm, a co-culture experiment was carried out as described above. Prior to co-culturing, astrocytes-22bpCy3 were treated for $10 \mathrm{~min}$ at $37^{\circ} \mathrm{C}$ with RNase A/T1 cocktail $(0.4 \mu \mathrm{g} / \mu 1$, Thermo Scientific) to degrade any synthetic sRNA residues attached to astrocyte membranes, as described elsewhere [39]. Transfer of $22 \mathrm{bpCy} 3$ to PC14 cells was examined by FACS as described above.

\section{Transwell assay}

PC14 cells were prevented from direct contact with astrocytes-22bpCy3 by a semipermeable $0.2-\mu \mathrm{m}$-pore transwell membrane (Corning Costar). In brief, astrocyte$22 \mathrm{bpCy} 3\left(2.5 \times 10^{5}\right.$ cells in $1 \mathrm{ml}$ of medium $)$ were plated in the lower chamber and PC14 cells $\left(4 \times 10^{5}\right.$ cells, in $1 \mathrm{ml}$ of medium) were added in 6-well plates to the upper compartment. The cells were incubated for $6 \mathrm{~h}$ at $37^{\circ} \mathrm{C}$. Transfer of $22 \mathrm{bpCy} 3$ to $\mathrm{PC} 14$ cells was examined by FACS as described above.

\section{Co-culturing and analysis of intercellular transfer of endogenous sRNAs}

Astrocytes and PC14 cells were plated, separately or as co-cultures, at a tumor cell to astrocyte ratio of $1: 1$, onto 35-mm-diameter wells of 6-well tissue-culture multiwell dishes. The cells were incubated at $37^{\circ} \mathrm{C}$ in a humidified $5 \% \mathrm{CO}_{2}$ incubator for $6 \mathrm{~h}$, harvested, and stained for $15 \mathrm{~min}$ at RT with APC anti-human CD340 Ab to label PC14 cells and with anti-mouse GLAST-PE conjugated antibody (Miltenyi Biotec) to label astrocytes. To obtain a single-cell uspension, the cells were pretreated as described above to dissociate cell conjugates. PC14-CD340-APC cells were separated from GLAST-PE-labeled astrocytes (hereafter astrocytes-GLAST-PE) by a FACSAria ${ }^{\mathrm{TM}}$ sorter at $4^{\circ} \mathrm{C}$ using FACSDiva ${ }^{\mathrm{TM}}$ software. The PE signal was detected 
by excitation with a 561 laser through a $582 / 15$ bandpass filter, and the APC signal by excitation with a 633 laser through a 660/20 bandpass filter. For each experiment, cells missing specific staining were analyzed to establish the background signal and to set gates for the sorting of positive cells. RNA was purified by TRIzol ${ }^{\circledR}$ reagent (Life Technologies) according to manufacturer's instructions, and mouse sRNA levels in PC14 cells cultured in the presence or absence of astrocytes were measured by microRNA microarray.

\section{miRNA microarray}

miRNA microarray was conducted as described previously [68]. miRNAs were extracted using TRIzol ${ }^{\circledR}$. RNA quantity and quality were determined using a

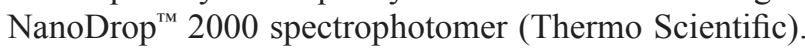
Affymetrix GeneChip ${ }^{\circledR}$ miRNA 2.0 arrays were used for genome-wide miRNA-expression analysis $(15,644$ probe sets for 131 organisms, including 1105 mature human miRNAs, 1105 human pre-miRNAs, 722 mature mouse miRNAs and 690 mouse pre-miRNAs) according to the instruction manual (Affymetrix, Santa Clara). Two biological repeats were used for each treatment.

\section{Bioinformatics analysis}

Microarray analysis was performed on CEL files using Partek ${ }^{\circledR}$ Genomics Suite ${ }^{\text {TM }}$ software (Partek GS; Partek). Quantile normalization was performed by the Robust Multi-array Average method (RMA), followed by One-way ANOVA. Mouse sRNAs that were differentially expressed $(P<0.05$; fold-change cutoff of 1.7$)$ were obtained.

\section{miRNA-real time PCR}

Total RNA was extracted from PC14 cells using TRIzol ${ }^{\circledR}$ reagent. RNA quantity and quality were determined using NanoDrop ${ }^{\mathrm{TM}}$. Four additional biological repeats (total of 6 repeats) were subjected to miRNA real-time (RT)-PCR using specific TaqMan ${ }^{\circledR}$ Small RNA probe sets for mmumiR-16*, mmu-miR-709, mmu-miR-1195, endogenous siRNA-1196 (endo-siRNA, custom made, sequence: AAAUCUACCUGCCUCUGCCU), mmu-miR-346, and mmu-miR-669c (Applied Biosystems). miRNA expression is represented relative to the expression of the internal control U6-snRNA. Data were analyzed by the $2^{-\Delta \Delta C t}$ method using 7300 RT-PCR system software (Applied Biosystems).

\section{Inhibition of gap-junction communication and analysis of intercellular transfer of endogenous SRNAs}

To inhibit gap-junction communication between astrocytes-22bpCy3 and PC14-GFP cells, both cell types were separately incubated with CBX $(50 \mu \mathrm{M} / 150 \mu \mathrm{M})$ for $16 \mathrm{~h}$. Cells were then co-cultured for $6 \mathrm{~h}$ in the continuing presence of $\mathrm{CBX}$ at $37^{\circ} \mathrm{C}$ in a humidified $5 \%$ $\mathrm{CO}_{2}$ incubator. To obtain a single-cell suspension, cells were pretreated as described above to dissociate the cell conjugates. GFP-transfected PC14 cells were separated from astrocytes by a FACSAria ${ }^{\mathrm{TM}}$ sorter at $4^{\circ} \mathrm{C}$ using FA CSDiva $^{\mathrm{TM}}$ software. Viable single cells were gated using side and forward scatter, with subsequent discrimination of doublets. GFP signal was detected following excitation with a 488 laser through a 530/30 bandpass filter. For each experiment, cells missing specific staining were analyzed to establish the background signal and to set gates for the sorting of positive cells. RNA was extracted, quantified, and subjected to miRNA RT-PCR for mmu-miR-16*, mmu-miR-709, mmu-miR-1195 and endo-siRNA-1196, as described above.

\section{Transfection of miRNA mimic and miR-Vec vector}

PC14 cells were plated in 96-well plates $\left(0.8 \times 10^{4}\right.$ cells/well). After $24 \mathrm{~h}$ the cells were transfected with TransIT $^{\circledR} \times 2$ (Mirus) with mimic-mmu-709, miRVec-16*, miR-Vec-1195, miR-Vec-1196 or, as controls, with either mimic negative control or with empty miRVec plasmid, a modified pMSCV- Blasticidin vector described elsewhere [47]. Cells were transfected with all possible combinations of the four miRNAs. After $24 \mathrm{~h}$ the cells were treated with $25 \mathrm{nM}$ Taxol for $48 \mathrm{~h}$. Cell viability was measured by MTT assay.

\section{MTTassay}

Cells were incubated with MTT solution at a final concentration of $0.5 \mathrm{mg} / \mathrm{ml}$ for $1 \mathrm{~h}$ at $37^{\circ} \mathrm{C}$, and DMSO was then added. The plates were read on a micro-ELISA reader (Mannedorf) at a test wavelength of $570 \mathrm{~nm}$ and a reference wavelength of $630 \mathrm{~nm}$. Cell viability was calculated as the ratio of absorbance in treated cultures to absorbance in untreated control cultures.

\section{Statistical analysis}

Results are expressed as mean values \pm SEM. $P$ values were calculated by One-way ANOVA. Post-hoc analysis was performed by Fisher's least significant difference (LSD) test. All analyses were performed with SPSS software.

\section{ACKNOWLEDGMENTS}

We thank Prof. Isaiah J. Fidler for providing the $\mathrm{H}-2 \mathrm{~Kb}$-tsA58 astrocyte line.

We thank Dr. Ronit Haklai for her support. We thank Shirley Smith for scientific editing. 


\section{FUNDING}

This work was supported by the Israel Science Foundation (662/10).

\section{CONFLICTS OF INTEREST}

The authors declare no conflicts of interest.

\section{REFERENCES}

1. American Cancer Society. Cancer Facts \& Figures 2015. 2015.

2. Soffietti R, Ruda R, Mutani R. Management of brain metastases. J Neurol. 2002; 249:1357-69.

3. Ahluwalia M, Vogelbaum M, Chao S, Mehta M. Brain metastasis and treatment. F1000Prime Rep. 2014; 6. Available from: http://www.f1000.com/prime/reports/m/6/114/.

4. Li H, Fan X, Houghton J. Tumor microenvironment: The role of the tumor stroma in cancer. J Cell Biochem. 2007; 101:805-15.

5. Bhowmick NA, Neilson EG, Moses HL. Stromal fibroblasts in cancer initiation and progression. Nature. 2004; 432:332-7.

6. Franco OE, Shaw AK, Strand DW, Hayward SW. Cancer associated fibroblasts in cancer pathogenesis. Seminars in Cell and Developmental Biology. 2010; 21:33-9.

7. Räsänen $\mathrm{K}$, Vaheri A. Activation of fibroblasts in cancer stroma. Experimental Cell Research. 2010; 316:2713-22.

8. Sofroniew M V., Vinters H V. Astrocytes: Biology and pathology. Acta Neuropathol. 2010; 119:7-35.

9. Hoelzinger DB, Demuth T, Berens ME. Autocrine factors that sustain glioma invasion and paracrine biology in the brain microenvironment. Journal of the National Cancer Institute. 2007; 99:1583-93.

10. Seike T, Fujita K, Yamakawa Y, Kido MA, Takiguchi S, Teramoto N, Iguchi H, Noda M. Interaction between lung cancer cells and astrocytes via specific inflammatory cytokines in the microenvironment of brain metastasis. Clin Exp Metastasis. 2011; 28:13-25.

11. Sierra A, Price JE, García-Ramirez M, Méndez O, López L, Fabra A. Astrocyte-derived cytokines contribute to the metastatic brain specificity of breast cancer cells. Lab Invest. 1997; 77:357-68.

12. Nussbaum ES, Djalilian HR, Cho KH, Hall WA. Brain metastases: Histology, multiplicity, surgery, and survival. Cancer. 1996; 78:1781-8.

13. Gerstner ER, Fine RL. Increased permeability of the blood-brain barrier to chemotherapy in metastatic brain tumors: Establishing a treatment paradigm. J Clin Oncol. 2007; 25:2306-3212.

14. Kemper EM, Van Zandbergen AE, Cleypool C, Mos HA, Boogerd W, Beijnen JH, Van Tellingen O. Increased penetration of paclitaxel into the brain by inhibition of P-glycoprotein. Clin Cancer Res. 2003; 9:2849-55
15. Zhang RD, Price JE, Fujimaki T, Bucana CD, Fidler IJ. Differential permeability of the blood-brain barrier in experimental brain metastases produced by human neoplasms implanted into nude mice. Am J Pathol. 1992; 141:1115-24.

16. Hasegawa H, Ushio Y, Hayakawa T, Yamada K, Mogami H. Changes of the blood-brain barrier in experimental metastatic brain tumors. J Neurosurg. 1983; 59:304-10.

17. Kim SW, Choi HJ, Lee H-J, He J, Wu Q, Langley RR, Fidler IJ, Kim S-J. Role of the endothelin axis in astrocyte- and endothelial cell-mediated chemoprotection of cancer cells. Neuro Oncol. 2014; 16:1585-98. Available from: http://neurooncology.oxfordjournals.org/cgi/doi/10.1093/neuonc/nou128.

18. Lin Q, Balasubramanian K, Fan D, Kim S-J, Guo L, Wang H, Bar-Eli M, Aldape KD, Fidler IJ. Reactive astrocytes protect melanoma cells from chemotherapy by sequestering intracellular calcium through gap junction communication channels. Neoplasia. 2010; 12:748-54.

19. Kim S-J, Kim J-S, Park ES, Lee J-S, Lin Q, Langley RR, Maya M, He J, Kim S-W, Weihua Z, Balasubramanian K, Fan D, Mills GB, et al. Astrocytes upregulate survival genes in tumor cells and induce protection from chemotherapy. Neoplasia. 2011; 13:286-98.

20. Luqmani $\mathrm{Y}$ a. Mechanisms of drug resistance in cancer chemotherapy. Med Princ Pract. 2005; 14 1:35-48.

21. Iwasa Y, Nowak MA, Michor F. Evolution of resistance during clonal expansion. Genetics. 2006; 172:2557-66.

22. Glasspool RM, Teodoridis JM, Brown R. Epigenetics as a mechanism driving polygenic clinical drug resistance. $\mathrm{Br} \mathrm{J}$ Cancer. 2006; 94:1087-92.

23. Fojo T. Multiple paths to a drug resistance phenotype: Mutations, translocations, deletions and amplification of coding genes or promoter regions, epigenetic changes and microRNAs. Drug Resist Updat. 2007; 10:59-67.

24. Duesberg P, Li R, Sachs R, Fabarius A, Upender MB, Hehlmann R. Cancer drug resistance: the central role of the karyotype. Drug Resist Updat. 2007; 10:51-8. Available from: http://www.ncbi.nlm.nih.gov/pubmed/17387035.

25. Chekulaeva M, Filipowicz W. Mechanisms of miRNAmediated post-transcriptional regulation in animal cells. Current Opinion in Cell Biology. 2009; 452-60.

26. Bushati N, Cohen SM. microRNA functions. Annu Rev Cell Dev Biol. 2007; 23:175-205.

27. Zhang C. Novel functions for small RNA molecules. Curr Opin Mol Ther. 2009; 11:641-51.

28. Miller TE, Ghoshal K, Ramaswamy B, Roy S, Datta J, Shapiro CL, Jacob S, Majumder S. MicroRNA-221/222 confers tamoxifen resistance in breast cancer by targeting p27Kip1. J Biol Chem. 2008; 283:29897-903.

29. Cho WCS, Chow ASC, Au JSK. Restoration of tumour suppressor hsa-miR-145 inhibits cancer cell growth in lung adenocarcinoma patients with epidermal growth factor receptor mutation. Eur J Cancer. 2009; 45:2197-206. 
30. Fang L, Li H, Wang L, Hu J, Jin T, Wang J, Yang BB. MicroRNA-17-5p promotes chemotherapeutic drug resistance and tumour metastasis of colorectal cancer by repressing PTEN expression. Oncotarget. 2014; 5:2974-87. Available from: http://www.ncbi.nlm.nih.gov/ pubmed/24912422. doi: 10.18632/oncotarget.1614.

31. Chatterjee A, Chattopadhyay D, Chakrabarti G. miR-16 targets Bcl-2 in paclitaxel-resistant lung cancer cells and overexpression of miR-16 along with miR-17 causes unprecedented sensitivity by simultaneously modulating autophagy and apoptosis. Cell Signal. 2015; 27:189-203. Available from: http://linkinghub.elsevier.com/retrieve/pii/ S0898656814003775.

32. Garofalo M, Quintavalle C, Di Leva G, Zanca C, Romano G, Taccioli C, Liu CG, Croce CM, Condorelli G. MicroRNA signatures of TRAIL resistance in human non-small cell lung cancer. Oncogene. 2008; 27:3845-55.

33. Tanase C, Albulescu R, Codrici E, Popescu ID, Mihai S, Enciu AM, Cruceru ML, Popa AC, Neagu AI, Necula LG, Mambet C, Neagu M. Circulating biomarker panels for targeted therapy in brain tumors. Future Oncol. 2014; 11:1-14. Available from: http:/www.ncbi.nlm.nih.gov/ pubmed/25241806.

34. Møller HG, Rasmussen AP, Andersen HH, Johnsen KB, Henriksen M, Duroux M. A systematic review of MicroRNA in glioblastoma multiforme: Micro-modulators in the mesenchymal mode of migration and invasion. Mol Neurobiol. 2013; 47:131-44.

35. Malzkorn B, Wolter M, Liesenberg F, Grzendowski M, Stühler K, Meyer HE, Reifenberger G. Identification and functional characterization of microRNAs involved in the malignant progression of gliomas. Brain Pathol. 2010; 20:539-50.

36. Mello CC, Conte D. Revealing the world of RNA interference. Nature. 2004; 431:338-42.

37. Mittelbrunn M, Gutiérrez-Vázquez C, Villarroya-Beltri C, González S, Sánchez-Cabo F, González MÁ, Bernad A, Sánchez-Madrid F. Unidirectional transfer of microRNAloaded exosomes from $\mathrm{T}$ cells to antigen-presenting cells. Nat Commun. 2011; 2:282.

38. Montecalvo A, Larregina AT, Shufesky WJ, Stolz DB, Sullivan MLG, Karlsson JM, Baty CJ, Gibson G a., Erdos G, Wang Z, Milosevic J, Tkacheva O a., et al. Mechanism of transfer of functional microRNAs between mouse dendritic cells via exosomes. Blood. 2012; 119:756-66.

39. Valadi H, Ekström K, Bossios A, Sjöstrand M, Lee JJ, Lötvall JO. Exosome-mediated transfer of mRNAs and microRNAs is a novel mechanism of genetic exchange between cells. Nat Cell Biol. 2007; 9:654-9.

40. Rechavi O, Erlich Y, Amram H, Flomenblit L, Karginov F V., Goldstein I, Hannon GJ, Kloog Y. Cell contact-dependent acquisition of cellular and viral nonautonomously encoded small RNAs. Genes Dev. 2009; 23:1971-9.

41. Kizana E, Cingolani E, Marbán E. Non-cell-autonomous effects of vector-expressed regulatory RNAs in mammalian heart cells. Gene Ther. 2009; 16:1163-8.
42. Katakowski M, Buller B, Wang X, Rogers T, Hospital HF. Functional microRNA is transferred between glioma cells. 2011; 70:8259-63.

43. Lim PK, Bliss S a., Patel S a., Taborga M, Dave M a., Gregory L a., Greco SJ, Bryan M, Patel PS, Rameshwar P. Gap junction-mediated import of microRNA from bone marrow stromal cells can elicit cell cycle quiescence in breast cancer cells. Cancer Res. 2011; 71:1550-60.

44. Pegtel DM, Cosmopoulos K, Thorley-Lawson D a, van Eijndhoven $\mathrm{M}$ a J, Hopmans ES, Lindenberg JL, de Gruijl TD, Würdinger T, Middeldorp JM. Functional delivery of viral miRNAs via exosomes. Proc Natl Acad Sci U S A. 2010; 107:6328-33.

45. Langley RR, Fan D, Guo L, Zhang C, Lin Q, Brantley EC, McCarty JH, Fidler IJ. Generation of an immortalized astrocyte cell line from $\mathrm{H}-2 \mathrm{~K}$ b-tsA58 mice to study the role of astrocytes in brain metastasis. Int J Oncol. 2009; 35:665-72.

46. Li H, Wu C, Aramayo R, Sachs MS, Harlow ML. Synaptic vesicles contain small ribonucleic acids (sRNAs) including transfer RNA fragments (trfRNA) and microRNAs (miRNA). Sci Rep. 2015; 5:14918. Available from: http://www.nature.com/doifinder/10.1038/srep14918.

47. Voorhoeve PM, Sage C Le, Schrier M, Gillis AJM, Stoop H, Nagel R, Liu YP, Duijse J Van, Drost J, Griekspoor A, Zlotorynski E, Yabuta N, Vita G De, et al. A genetic screen implicates miRNA-372 and miRNA-373 as oncogenes in testicular germ cell tumors. Adv Exp Med Biol. 2007; 604:17-46.

48. Park ES, Kim S-J, Kim SW, Yoon S-L, Leem S-H, Kim S-B, Kim SM, Park Y-Y, Cheong J-H, Woo HG, Mills GB, Fidler IJ, Lee J-S. Cross-species hybridization of microarrays for studying tumor transcriptome of brain metastasis. Cancer Res. 2012; 72:4283-4283.

49. Liu T, Zhang X, Sha K, Liu X, Zhang L, Wang B. miR-709 up-regulated in hepatocellular carcinoma, promotes proliferation and invasion by targeting GPC5. Cell Prolif. 2015; 48:330-7. Available from: http://doi.wiley. com/10.1111/cpr.12181.

50. Tamminga J, Kathiria P, Koturbash I, Kovalchuk O. DNA damage-induced upregulation of miR-709 in the germline downregulates BORIS to counteract aberrant DNA hypomethylation. Cell Cycle. 2008; 7:3731-6.

51. Tang R, Li L, Zhu D, Hou D, Cao T, Gu H, Zhang J, Chen J, Zhang C-Y, Zen K. Mouse miRNA-709 directly regulates miRNA-15a/16-1 biogenesis at the posttranscriptional level in the nucleus: evidence for a microRNA hierarchy system. Cell Res. 2012; 22:504-15. Available from: http://dx.doi. org/10.1038/cr.2011.137.

52. Zhao Z, Han C, Liu J, Wang C, Wang Y, Cheng L. GPC5, a tumor suppressor, is regulated by miR620 in lung adenocarcinoma. Mol Med Rep. 2014; 2540-6. Available from: http://www.spandidos-publications.com/10.3892/ mmr.2014.2092. 
53. Li X, Sanda T, Look a T, Novina CD, von Boehmer H. Repression of tumor suppressor miR-451 is essential for NOTCH1-induced oncogenesis in T-ALL. J Exp Med. 2011; 208:663-75.

54. Tagne J-B, Mohtar OR, Campbell JD, Lakshminarayanan M, Huang J, Hinds AC, Lu J, Ramirez MI. Transcription factor and microRNA interactions in lung cells: an inhibitory link between NK2 homeobox 1, miR-200c and the developmental and oncogenic factors Nfib and Myb. Respir Res. 2015; 16:1-11. Available from: http://respiratoryresearch.com/content/16/1/22.

55. Mu D. The complexity of thyroid transcription factor 1 with both pro- and anti-oncogenic activities. J Biol Chem. 2013; 288:24992-5000.

56. Kwei KA, Kim YH, Girard L, Kao J, Pacyna-Gengelbach M, Salari K, Lee J, Choi Y-L, Sato M, Wang P, HernandezBoussard T, Gazdar AF, Petersen I, et al. Genomic profiling identifies TITF1 as a lineage-specific oncogene amplified in lung cancer. 2010; 9:1-14.

57. Castellano L, Stebbing J. Deep sequencing of small RNAs identifies canonical and non-canonical miRNA and endogenous siRNAs in mammalian somatic tissues. Nucleic Acids Res. 2013; 41:3339-51.

58. Claycomb JM. Ancient endo-siRNA pathways reveal new tricks. Curr Biol. 2014; 24:R703-15. Available from: http:// dx.doi.org/10.1016/j.cub.2014.06.009.

59. Okamura K, Phillips MD, Tyler DM, Duan H, Chou Y, Lai EC. The regulatory activity of microRNA* species has substantial influence on microRNA and 3' UTR evolution. Nat Struct Mol Biol. 2008; 15:354-63.

60. Yang X, Du WW, Li H, Liu F, Khorshidi A, Rutnam ZJ, Yang BB. Both mature miR-17-5p and passenger strand miR-17-3p target TIMP3 and induce prostate tumor growth and invasion. Nucleic Acids Res. 2013; 41:9688-704.
61. Henman FD. Inhibition of peptic activity by carbenoxolone and glycyrrhetinic acid. Gut. 1970; 11:344-51.

62. Connors BW. Tales of a dirty drug: carbenoxolone, gap junctions, and seizures. Epilepsy Curr. 2012; 12:66-8. Available from: http://www.pubmedcentral.nih.gov/ articlerender.fcgi? artid $=3316363 \&$ tool $=$ pmcentrez\&render type $=$ abstract.

63. Fonseca PC, Nihei OK, Savino W, Spray DC, Alves LA. Flow cytometry analysis of gap junction-mediated Cel-Cell communication: Advantages and pitfalls. Cytom Part A. 2006; 69:487-93.

64. Zündorf G, Kahlert S, Reiser G. Gap-junction blocker carbenoxolone differentially enhances NMDA-induced cell death in hippocampal neurons and astrocytes in co-culture. J Neurochem. 2007; 102:508-21.

65. Moradi S, Charkhpour M, Ghavimi H, Motahari R, Ghaderi M, Hassanzadeh K. Gap junction blockers: a potential approach to attenuate morphine withdrawal symptoms. J Biomed Sci. 2013; 20:77. Available from: http://www.pubmedcentral. nih.gov/articlerender.fcgi?artid $=4015126 \&$ tool $=$ pmcentrez \&rendertype $=$ abstract.

66. Ozog M a, Siushansian R, Naus CC. Blocked gap junctional coupling increases glutamate-induced neurotoxicity in neuron-astrocyte co-cultures. J Neuropathol Exp Neurol. 2002; 61:132-41.

67. Nickel R, Becker D, Forge A. Molecular and functional characterization of gap junctions in the avian inner ear. $\mathrm{J}$ Neurosci. 2006; 26:6190-9. Available from: http://www. ncbi.nlm.nih.gov/pubmed/16763027.

68. Zitman-Gal T, Green J, Pasmanik-Chor M, Golan E, Bernheim J, Benchetrit S. Vitamin D manipulates miR-181c, miR-20b and miR-15a in human umbilical vein endothelial cells exposed to a diabetic-like environment. Cardiovasc Diabetol. 2014; 13:8. 